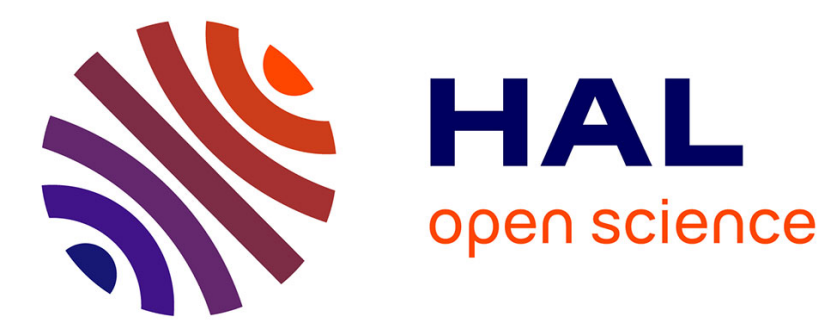

\title{
Magnetic resonance sialography in bilateral Stafne bone cavities
}

Cédric Mauprivez, M Sahli Amor, Roman H Khonsari

\section{To cite this version:}

Cédric Mauprivez, M Sahli Amor, Roman H Khonsari. Magnetic resonance sialography in bilateral Stafne bone cavities. Journal of Oral and Maxillofacial Surgery, 2015, 73 (5), pp.934.e1-934.e7. 10.1016/j.joms.2015.01.034 . hal-01117128

\section{HAL Id: hal-01117128 \\ https://hal.sorbonne-universite.fr/hal-01117128}

Submitted on 16 Feb 2015

HAL is a multi-disciplinary open access archive for the deposit and dissemination of scientific research documents, whether they are published or not. The documents may come from teaching and research institutions in France or abroad, or from public or private research centers.
L'archive ouverte pluridisciplinaire HAL, est destinée au dépôt et à la diffusion de documents scientifiques de niveau recherche, publiés ou non, émanant des établissements d'enseignement et de recherche français ou étrangers, des laboratoires publics ou privés. 


\section{ACCEPTED MANUSCRIPT}

\section{Magnetic resonance sialography in bilateral Stafne bone cavities}

Mauprivez $\mathrm{C}^{1,2}$ (consultant), Sahli Amor $\mathrm{M}^{3}$ (consultant), Khonsari $\mathrm{RH}^{4,5}$ (assistant professor)

1. Service d'Odontologie, Assistance Publique des Hôpitaux de Paris, Groupe Hospitalier Pitié-Salpêtrière, Paris, France

2. UFR d'Odontologie, Université Paris-Diderot, Paris, France

3. Service de Neuroradiologie, Assistance Publique des Hôpitaux de Paris, Groupe Hospitalier Pitié-Salpêtrière, Paris, France

4. APHP - Hôpital Pitié-Salpêtrière, Service de Chirurgie Maxillofaciale et Stomatologie, F75013, Paris, France

5. Sorbonne Universités, UPMC Université Paris 06, UFR Médecine, F-75005, Paris, France

\section{Corresponding author}

RH Khonsari

AP-HP, Hôpital Pitié-Salpêtrière, Service de Chirurgie Maxillofaciale et Stomatologie, Paris, F-75013, France ; UPMC Université Paris 06, F-75005, Paris, France

tel $\quad 0033142161361$

fax $\quad 0033145245998$

email roman.khonsari@gmail.com 
Introduction Stafne bone cavities (SBC) are mandibular radiolucent lesions with challenging differential diagnoses. Many radiological methods have been proposed to demonstrate the presence of salivary gland tissues inside the cavities.

Case report We report a case of bilateral angular mandibular radiolucent cavities located below the mandibular nerve canal. Magnetic resonance imaging (MRI) showed continuity between the submandibular glands and the tissue herniated into the cavities. The ductal system of both submandibular glands was evaluated using magnetic resonance sialography (MR sialography). We report an opacification of the glandular ductal system from the contents of the cavities up to its primary branches, confirming the diagnosis of SBC.

Discussion MR sialography allows to image submandibular gland ducts and demonstrates the presence of salivary gland tissue inside mandibular cavities with precise topographical information. This technique does not involve canulation or injection of contrast agents, and does not expose patient to radiations. MR sialography is a valuable addition to the common imaging procedures used in the investigation of SBCs.

\section{Keywords}

Stafne bone cavity; magnetic resonance imaging; magnetic resonance sialography 


\section{Introduction}

The diagnosis of Stafne bone cavities is challenging. According to many authors, the most reliable method for assessing this diagnosis is computed tomography sialography (CT sialography). ${ }^{1-3}$ This invasive technique involves cannulation of the salivary ducts, local injection of contrast agent and exposure to radiations. This article reports a case of Stafne bone cavities diagnosed using magnetic resonance sialography (MR sialography) and discusses this less invasive technique as a valuable alternative to CT sialography. 


\section{Case report}

An 80-year-old man was referred by the local neurology department for the screening of dental infections. He had no relevant medical history. Panoramic radiograph showed bilateral symmetric well-defined radiolucent lesions in the region of the mandibular third molars

(Figure 1). Both lesions were located below the mandibular canal. The right radiolucent lesion was 1.5 x $1.2 \mathrm{~cm}$ in size, round, well-circumscribed and corticated. The left radiolucent lesion was $1.5 \times 0.5 \mathrm{~cm}$ in size, ovoid, with no sclerotic borders. The patient had no history of trauma and the lesions were not tender. The main hypothesis was a bilateral posterior variant of SBC. Magnetic resonance imaging (MRI) showed that the bone cavities were filled with soft tissues, continuous with the submandibular glands. MR images were obtained on a 1,5 mm (SIEMENS Magnetom Aera 6448) device using both head and neck surface coils. Fast spin echo (FSE) T1 weighted axial images with the following parameters were acquired: Repetition Time (TR): 422 ms., Echo Time (TE): 9.5 ms., matrix: 320 x 248 mm, section thickness: $3 \mathrm{~mm}$, examination period: 2 min $41 \mathrm{~s}$. T2 'DIXON' 2D fast spin echo (FSE) multiecho with fat and water separation images and the following parameters were also obtained: TR: 5440 ms., TE: $98-110$ ms., matrix 256 x 256mm, FOV: $210 \mathrm{~cm}^{2}$, section thickness 3.0 mm, examination period: 3 min $45 \mathrm{~s}$. MR sialography involved different sequences: 3D Sialo MRI, fat-saturated isotropic Turbo spin echo (width: 1 mm, matrix: 192 x 135 mm, FOV: 180 $\mathrm{cm}^{2}$, examination period: 3 min $53 \mathrm{~s}$.), with MIP (maximum intensity projection) and MP (multiplanar) reconstructions. The contents of the cavities emitted the same MR signal as the submandibular glands. MR sialography confirmed that the cavities were in continuity with the submandibular glands, with an opacification of the glandular ductal system up to its primary branches (Figure 3). A final diagnosis of bilateral SBC was retained. No further investigations or treatments were proposed. 


\section{Discussion}

SBC was initially described by Stafne in 1942 as an asymptomatic well-defined radiolucent defect located on the medial face of the mandible. ${ }^{1}$ The radiological incidence of SBC is 0.08 $0.48 \% .^{2,3}$ SBC predominantly affects men aged $50-70 .^{2,3}$ The usual localization of SBC (also called lingual posterior variant) is the submandibular region close to the inferior border of the mandible. The diagnostic criteria for SBC are: (1) homogenous round to ovoid radiolucency of the mandible, (2) sharp cortical limits with clear distinction from neighboring structures such as teeth, (3) ranging 1.0-3.0 $\mathrm{cm}$ in size, (4) typical localization below the inferior alveolar nerve canal, but limited by the mandibular angle and the lower borders of the horizontal branch and ramus. ${ }^{2,3}$ Variations in the presentation of SBC have been reported, such as multiple lesions, lesions above the mandibular canal and lesions without sclerotic margins. $^{3,4}$

Similar but more anterior defects have also been reported in the mandible near the apices of the premolars, associated with the sublingual glands (lingual anterior variant), and very rarely on the medial surface of the ramus, associated with the parotid gland (ramus variant). Usually, $\mathrm{SBC}$ is a unilateral condition. Bilateral occurrence is rare and multiple occurrences are even more uncommon. ${ }^{2}$ The origins and the mechanisms of disease are controversial. Several hypotheses have been proposed: incomplete calcification of Meckel's cartilage during ossification, trapping of the submandibular gland during ossification or trauma and compression from acquired vascular lesion of the facial artery. ${ }^{5}$ The rare occurrences of SBC at an early age are not in favor of a developmental disorder and most authors currently prefer theories involving the mechanical role of the submandibular glands in the formation of the cavities. ${ }^{6,7}$ In fact, aging submandibular glands are progressively subjected to non-specific inflammatory infiltrations with subsequent fibrosis, hypertrophy and hyperplasia. These 
processes gradually change the mechanical properties of the glands and induce enough pressure on the lingual mandibular cortical bone to cause local bone resorption.

The diagnosis of SBC is generally established on routine panoramic radiographs. Schneider et al. (2014) $)^{3}$ proposed a diagnostic algorithm for bony lesions initially supected to be SBC on a panoramic radiograph, involving first Cone beam CT (CBCT) and then MR imaging to solve difficult cases. In fact, when standard radiographs are not sufficient, CT or CBCT can help to establish the differential diagnosis with traumatic bone cysts, ameloblastoma, fibro-osseous lesions, central giant cell lesions, salivary gland tumors, metastasis and vascular malformations. ${ }^{8}$ Nevertheless, CT and CBCT do not provide optimal information on the contents of the cavities and MRI can help to characterize the soft tissues prolapsed into the defects. ${ }^{9}$

The combination of sialography with $\mathrm{CT}$ or $\mathrm{CBCT}^{10}$ has been suggested to confirm the diagnosis of SBC, allowing the assessment of salivary gland tissue with an opacification of the salivary ducts inside the bony cavity. However, CT sialography has several disadvantages such as pain due to the injection of the contrast agent and exposure to radiation. Furthermore, radiologists generally have little experience in salivary gland cannulation and this technique has a high incidence of failure. Some authors have thus recommended MRI as the primary diagnostic imaging technique. ${ }^{4,9}$

In the present case, MRI with conventional sequences showed that the mandibular bone cavities were filled with tissues similar to the submandibular gland. MR sialography allowed to obtain a hyperintense signal for fluid structures with removal of surrounding tissue on high T2-weighted sequences, and could thus highlight the salivary ductal system within the tissues herniated into the cavities. Using this technique, we could unequivocally confirm the diagnosis of SBC. 
MR sialography is a non-invasive technique and does not involve canulation, injections into the salivary ducts or exposure to radiations. MR sialography is based on the application of techniques initially developed for MR cholangio-pancreatography and urinary tract imaging to the head and neck region. The technical background of MR sialography is the concept of hydro-MR ${ }^{11}$ : fluids such as gall, urine or saliva induce a hyper-intense signal when surrounding tissues are removed on high T2-weighted sequences. Saliva is thus used as an inner contrast agent. Some authors propose to increase the contrast of MR sialography images by stimulating salivary secretion using sialagogues, hyper-hydration and lemon juice or tartaric acid administration before image acquisition. ${ }^{11}$ MR sialography tends to progressively replace sialography and has been validated as an alternative to conventional sialography in patients with sialolithiasis, radiation induced xerostomia and Sjögren syndrome. ${ }^{11-13} \mathrm{MR}$ sialography allows the study of the 4 major salivary glands (left and right submandibular and parotid glands) and of the surrounding soft-tissue structures in a single imaging session, while CT sialography would required several painful and technically challenging injections of contrast agent. ${ }^{12}$ Different MR sequences and protocols are reported in the literature for the evaluation of the submandibular ductal system: 3D CISS, 3D FSE with MPR, MIP and VR (volume rendering) reconstructions and 2D Sialo MRI with Turbo Spin Echo Single Short. ${ }^{11-}$ ${ }^{13}$ In our experience, the most clinically relevant images were obtained using 3D Sialo MRI with Turbo Spin Echo isotropic fat-saturated and reconstructions using MIP (Maximum Intensity Projection) and MPR (Multi Planar Reconstruction).

The disadvantages of MR sialography are similar to the disadvantages of standard MRI: availability, high cost, image acquisition length, counter-indication in patients with atrisk implantable devices (pacemakers) and in claustrophobic patients.

We believe MR sialography technique is a valuable alternative to CT sialography in the diagnostic algorithm of SBCs. 
No conflicts of interest. 


\section{References}

1. Stafne EC: Bone cavities situated near the angle of the mandible. J Am Dent Assoc 29:1969, 1942.

2. Philipsen HP, Takata T, Reichart PA, Sato S, Suei Y: Lingual and buccal mandibular bone depressions : a review based on 583 cases from a world-wide literature survey including 69 new cases from Japan. Dentomaxillofac Radiol 31:281, 2002.

3. Schneider T, Filo K, Locher MC, Gander T, Metzler P, Grätz KW, Kruse AL, Lübbers HT: Stafne bone cavities: systematic algorithm for diagnosis derived from retrospective data over a 5-year period. Br J Oral Maxillofac Surg 52:369, 2014.

4. Branstetter BF, Weissman JL, Kaplan SB: Imaging of a Stafne bone cavity: what MR adds and why a new name is needed. Am J Neuroradiol 20:587, 1999.

5. Minowa K, Inoue N, Sawamura T, Matsuda A, Totsuka Y, Nakamura M: Evaluation of static bone cavities with CT and MRI. Dentomaxillofac Radiol 32:2, 2003.

6. Ariji E, Fujiwara N, Tabata O, Nakayama E, Kanda S, Shirtsuchi Y, Oka M: Stafne's bone cavity. Classification based on outline and content determined by computed tomography. Oral Surg Oral Med Oral Pathol 76:375, 1993.

7. Shimizu M, Osa N, Okamura K, Yoshiura K: CT analysis of the Stafne's bone defects of the mandible. Dentomaxillofac Radiol 35:95, 2006.

8. Kopp S, Ihde S, Bienengraber V: Differential diagnosis of Stafne idiopathic bone cyst with volume tomography (DVT). J Maxillofac Oral Surg 9:80, 2010.

9. Probst FA, Probst M, Maistreli IZ, Otto S, Troeltzsch M: Imaging characteristic of Stafne bone cavity - panoramic radiography, computed tomography and magnetic resonance imaging. Oral Maxillofacial Surg 18:351, 2014.

10. Li B, Long X, Cheng Y, Wang S: Cone Beam CT sialography of Stafne bone cavity. Dentomaxillofac Radiol 40:519, 2011. 
11. Wada A, Uchida N, Yokokama M, Yoshizako T, Kitagaki H. Radiation induced xerostomia: objective evaluation of salivary gland injury using MR Sialography. Am J Neuroradiol 30:53, 2009.

12. Jäger L, Menauer F, Holzkwecht N, Scholtz V, Grevers G, Reiser M. Sialolithiasis: MR sialography of the submandibular duct, an alternative to conventional sialography and US? Radiology 216:665, 2000.

13. Tonami H, Ogawa Y, Motaba M, Kuginuki Y, Yokota H, Higashi K. MR Sialography in patients with Sjögren syndrome. AMJ Neuroradiol 19:1199, 1998. 
Figure legends

Figure 1. Panoramic radiograph. Well-defined bilateral radiolucent lesions in the right and left body of mandible, below the mandibular canal.

Figure 2. MR imaging showing that the mandibular bone cavities seen in Figure 1 are filled with tissue continuous with and similar to the submandibular glands (right cavity: blue arrow; left cavity: orange arrow).

(a) Axial T1-weighted MR image showing an isosignal for submandibular glands within the mandible and a gap in the hyposignal of the mandibular cortex.

(b, c) Axial T2 "DIXON" 2D fast spin echo (FSE) multi echo weighted images showing the submandibular gland hernia in the medulla of the mandible with an isosignal for the gland and a hypersignal for the ducts.

(d, e) Coronal T2 "DIXON" 2D fast spin echo (FSE) multi echo weighted images confirming the left submandibular glands hernia within the medulla of the mandible.

Figure 3. Axial reconstruction ("MIP" sialo-MRI) demonstrating that the bony cavities contain submandibular salivary gland tissue with an opacification of the ductal system within the herniated glandular tissue (right cavity: blue arrow; left cavity: orange arrow). 


\section{ACCEPTED MANUSCRIPT}

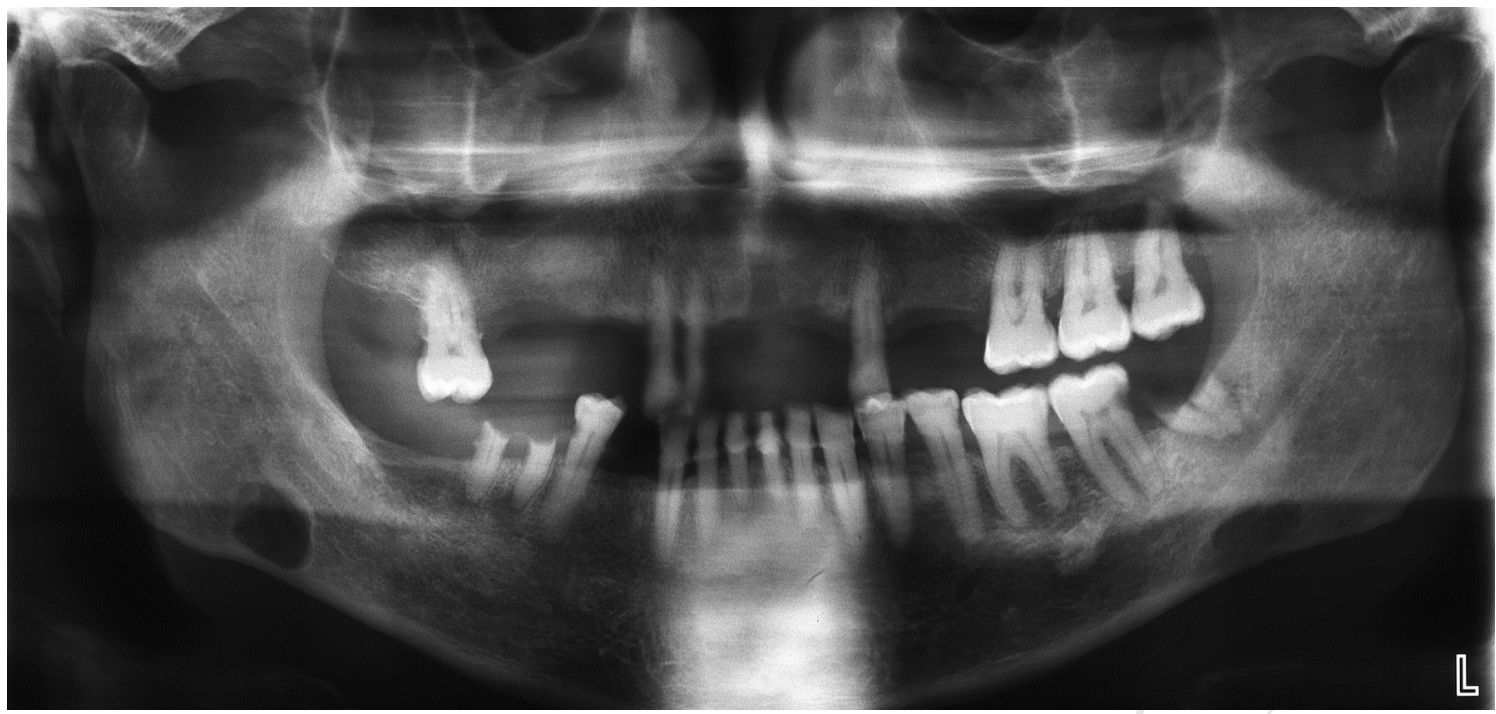



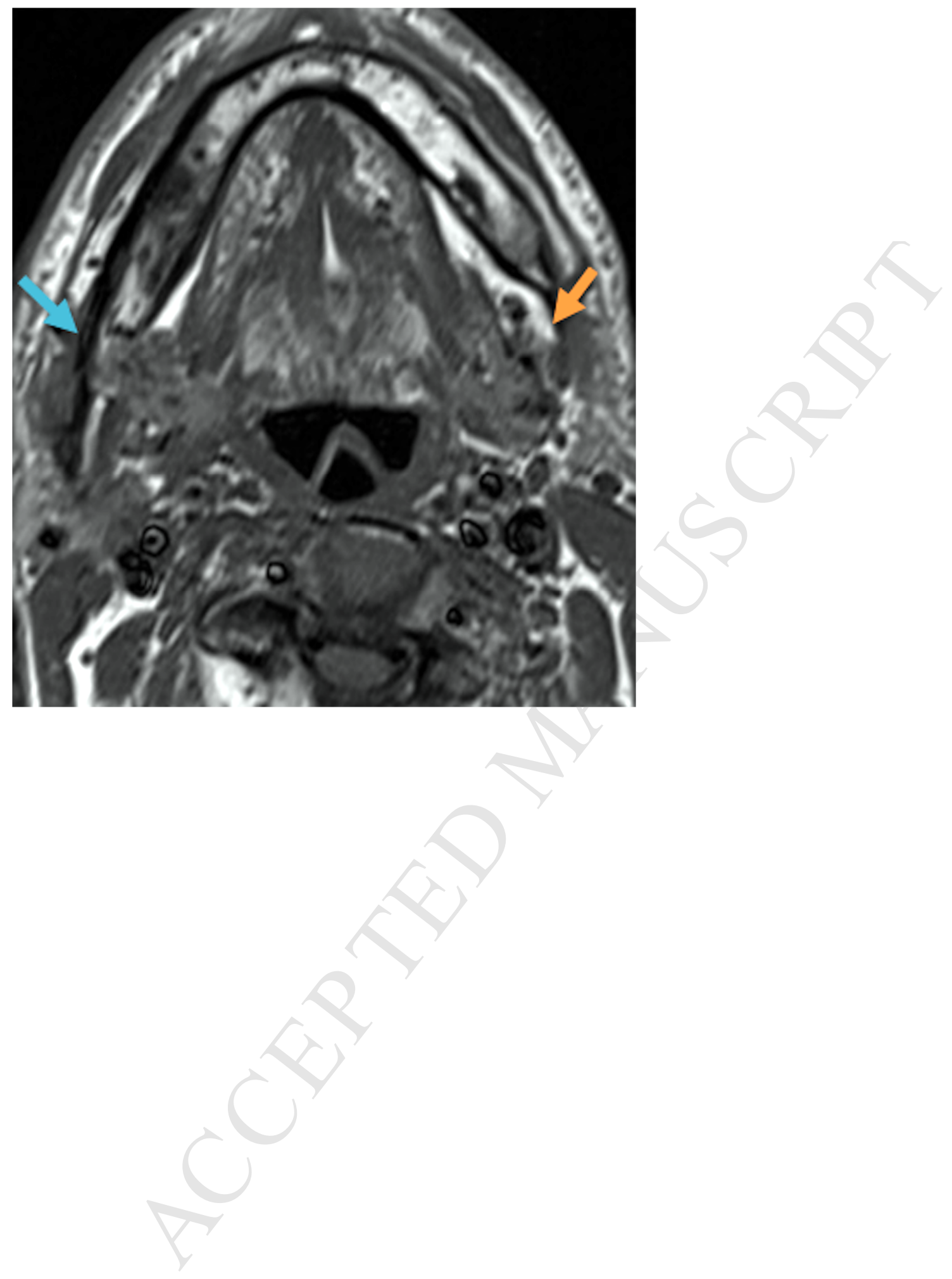


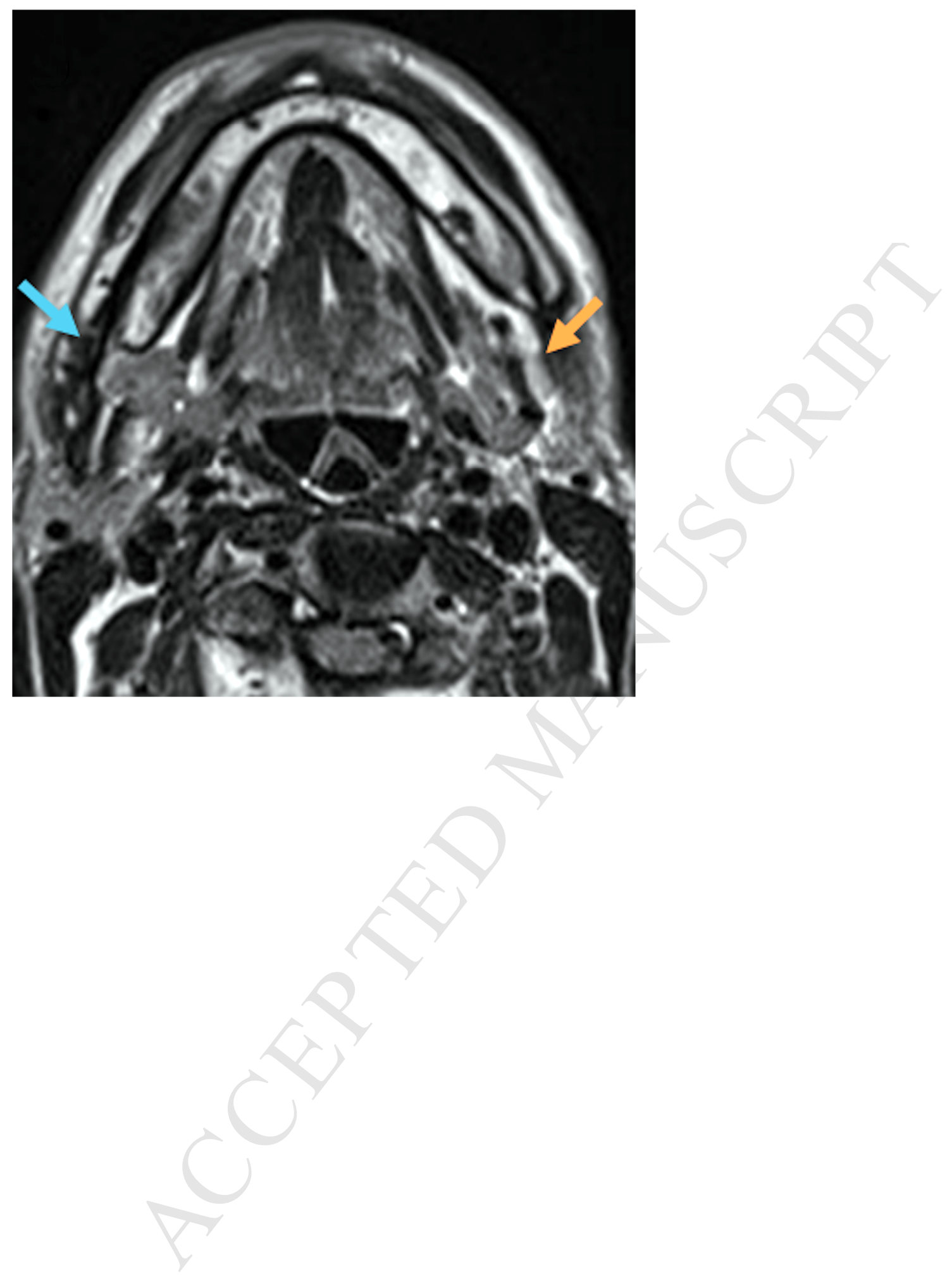



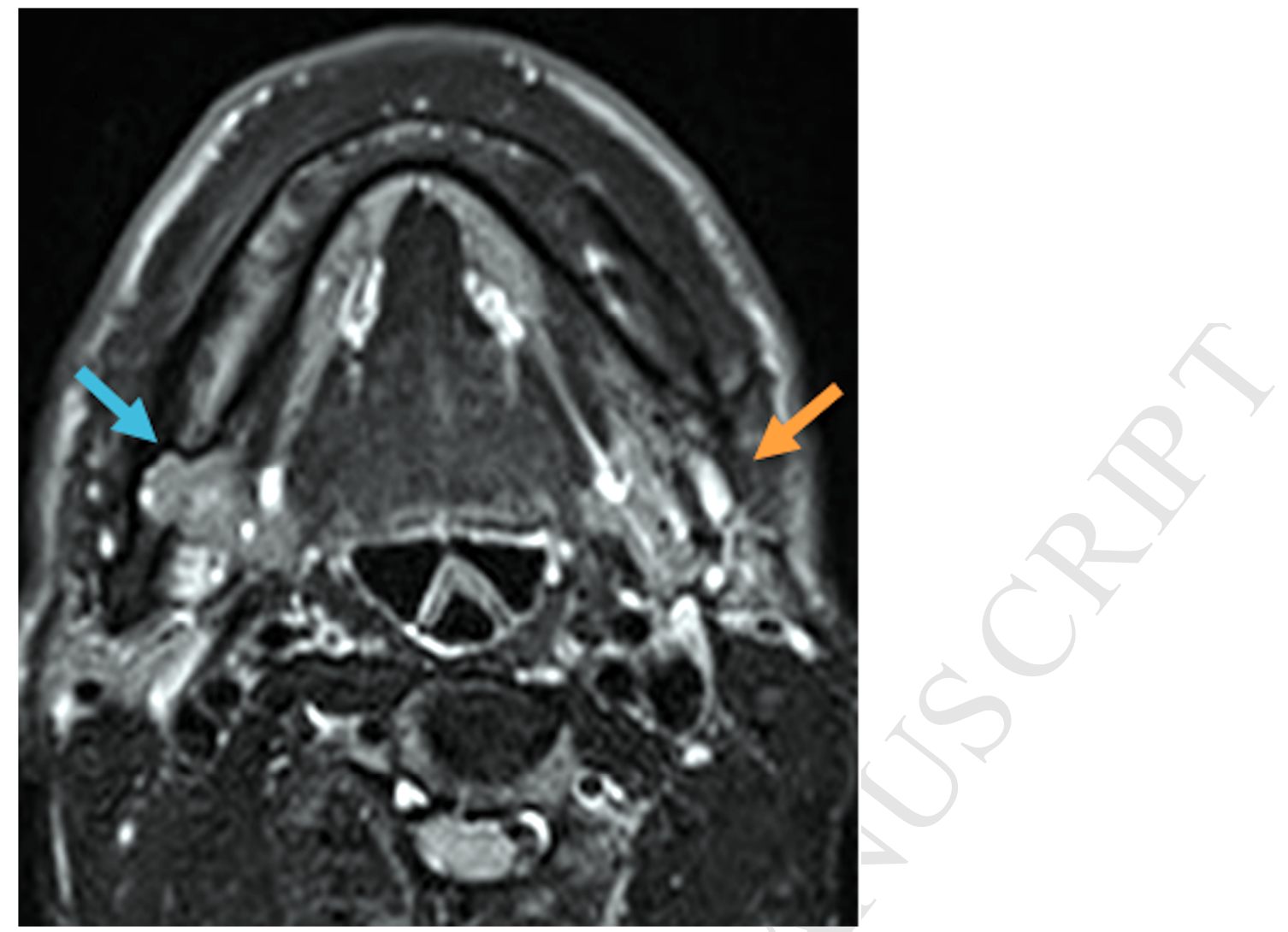


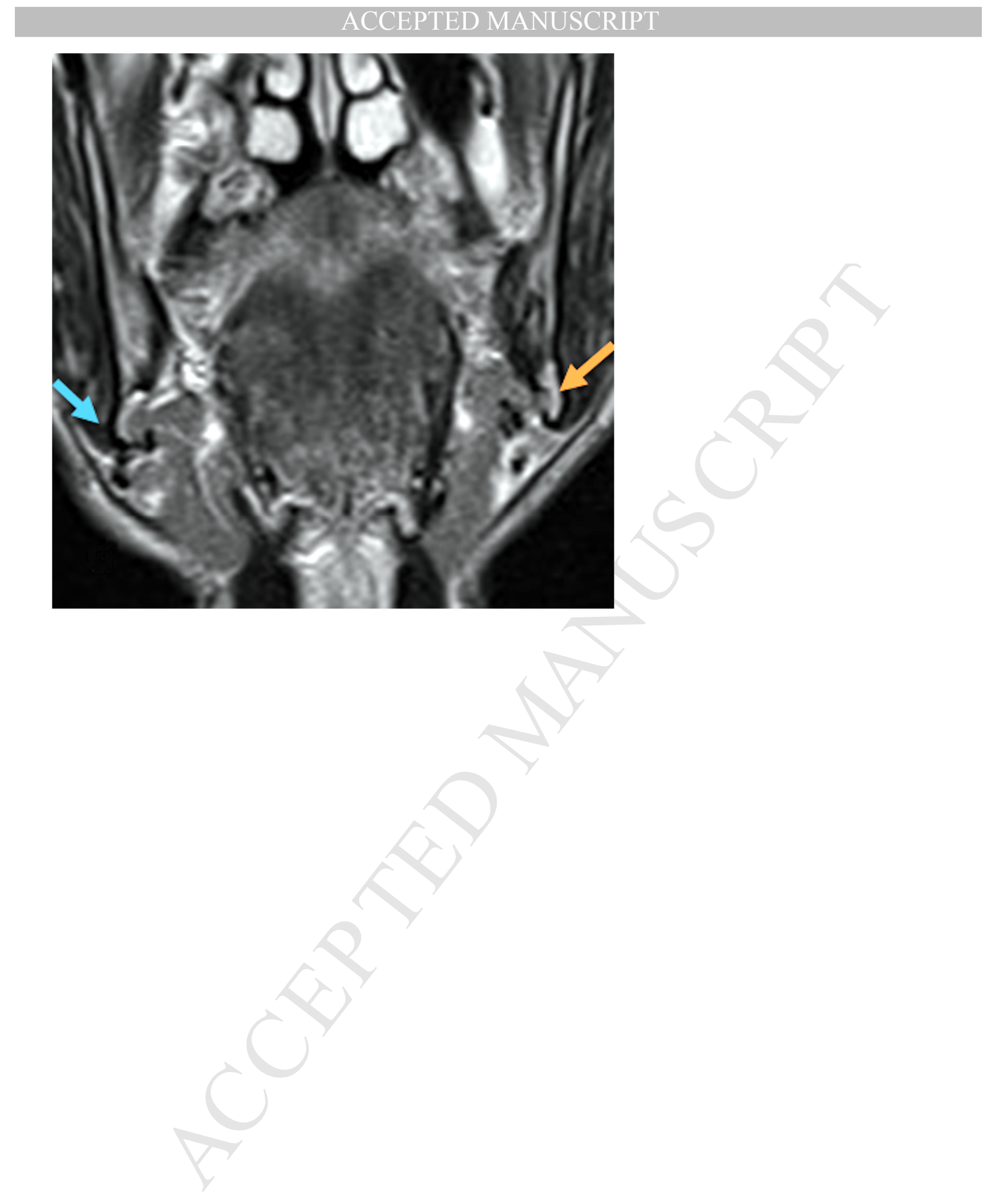




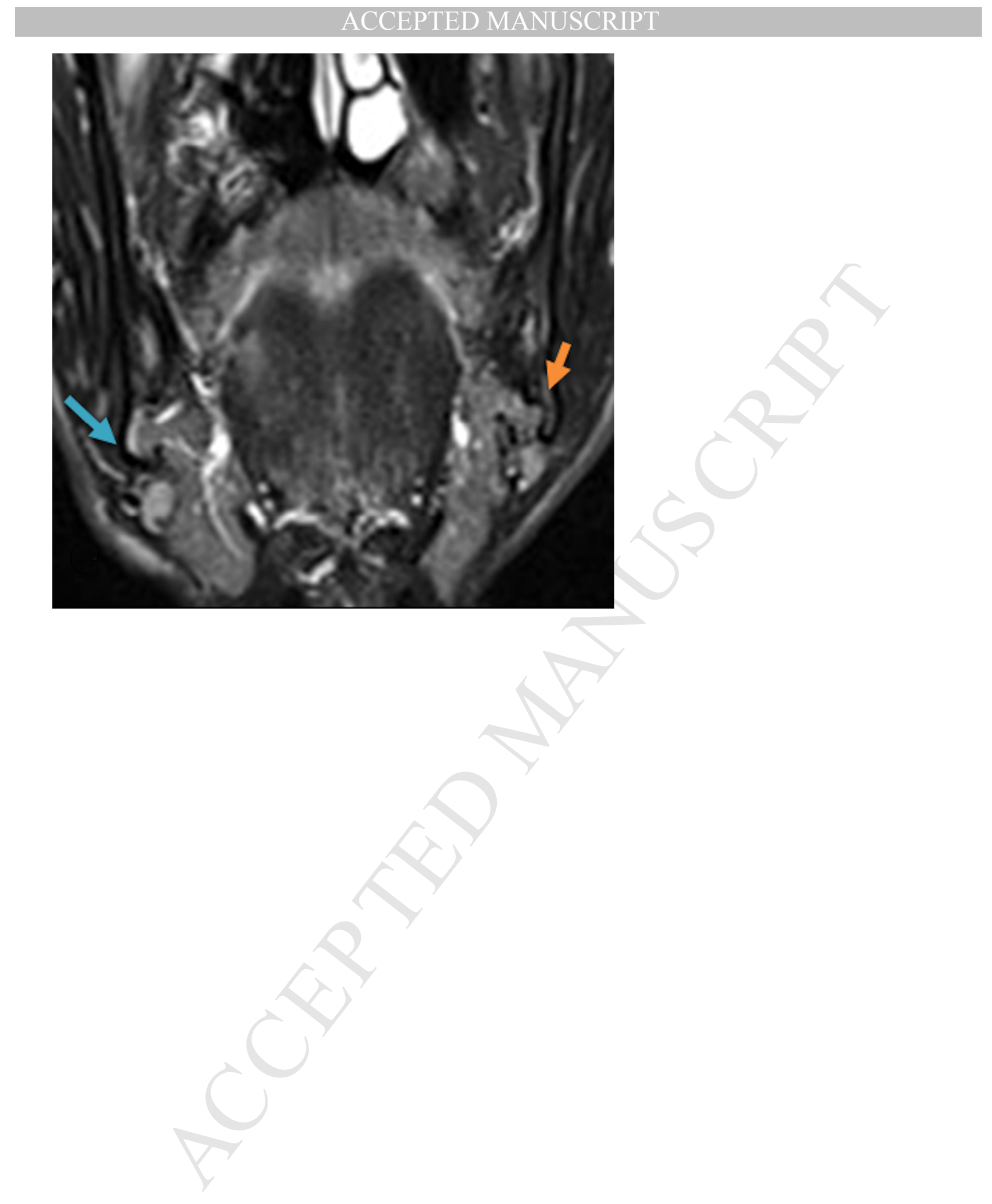




\section{ACCEPTED MANUSCRIPT}

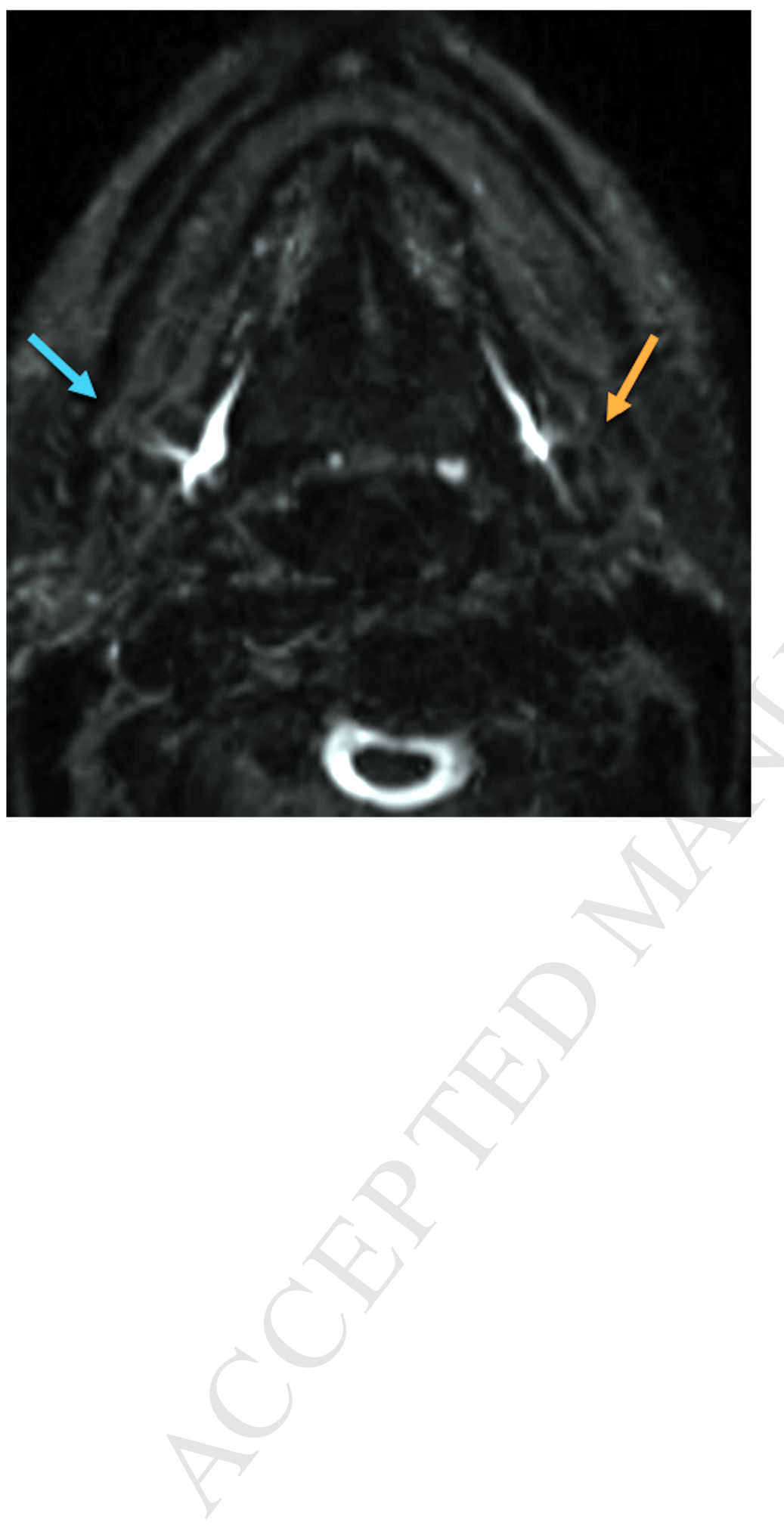

